\title{
E-Commerce Assessment in Fuzzy Situation
}

\author{
Mehdi Fasanghari \\ Iran Telecommunication Research Center (ITRC)
}

\section{Introduction}

Customer satisfaction degree is critical for e-commerce enterprises. Thus, more and more commercial organizations attend to "customer satisfaction " as their main strategy (Mihelis et al., 2001).

Customer satisfaction means the satisfaction degrees of customers purchasing commodities. Under electronic commerce, how to raise the consumers' degree of satisfaction and gain the consumers' loyalty has become the key factor relating with whether ecommerce enterprise can survive. The view of the philosophy of modern management scientific holds that, "customer satisfaction is the basic criteria of enterprise". Nowadays, more and more commercial organizations take customer satisfaction as their main strategy object (Mihelis et al., 2001).

Customer satisfaction and customer satisfaction index have been widely developed in both theory and applications (C. Albert, 2002, E.W. Anderson \& C. Fornell, 2000, P. Hackl et al., 2000, D.J. Michael, 2004). Fornell (C. Fornell, 1992) developed the first model of customer satisfaction in 1992. The American customer satisfaction index (ASCI) was set up in 1994 (Yin Rongwu, 2000), Swedish SCSI, European ECSI and Korean KCSI etc. Chinese Customer satisfaction Index (CCSI) started in 1998, are still on the stage of exploration and learning (Zhao Pengxiang, 2001).

Customer satisfaction has been used frequently in the quality system certification of ISO9000 of 2000 edition, which shows the important of this concept (Xiaohong Liu et al., 2008). Also, Many countries are conducting Customer Satisfaction Index studies since Customer Satisfaction Index can be used as a predicator for profitability and value of the organizations (S.-H. Hsu, 2008).

Nowadays, more attention has been paid to the problem of e-commerce customer satisfaction (M. Wang, 2003). The e-commerce customer satisfaction parameters should be visible for customers. The more important parameters have been chosen based on the literature review: independency, comparable, and feasibility (Mihelis et al., 2001, Yan XiaoTian \& Wei Hong-Jun, 2005, Yin Rongwu, 2000, Zheng Yue-Fang, 2005, Liu, 2007).

Each index should independently represent the service quality satisfaction from some aspect (Fasanghari \& Roudsari, 2008). While customers represent their satisfaction value of ecommerce, the indexes should be comparable for different customer. Thus, the indexes of ecommerce customer satisfaction have been obtained based on literature review so that support all of the customer satisfaction area for e-commerce. 
To evaluate the e-commerce customer satisfaction quantitatively, many countries established their own index of customer satisfaction degree, namely customer satisfactory Index, which is a new set of indexes evaluating an enterprise and a trade or an industry completely from customer's angle (Liu Peide, 2007).

The e-commerce customer satisfaction should pay attention to the parameters which are visible for customers. The more important parameters have been chosen based on the literature review: independency, comparable, and feasibility (Mihelis et al., 2001, Yan XiaoTian \& Wei Hong-Jun, 2005, Yin Rongwu, 2000, Zheng Yue-Fang, 2005).

Customer evaluation for e-commerce would be possible if the independency among the indexes exist. The selection of indexes, therefore, should be high enough in resolution to help distinguish the factors. Each index should independently represent the service quality satisfaction from some aspect.

To clarify, indexes should be comparable, as the model should evaluate the different customer inputs, which express the satisfaction value for e-commerce; consequently, the indexes should be comparable for different customer while they represent their satisfaction value of e-commerce.

At last, identification and reduction of customer satisfaction are the objective of e-commerce customer satisfaction. The title and content of each index, hence, should be well understood by the customers.

In this paper, in the next section, fuzzy set theory and the principals of triangular fuzzy number have been presented. Then, the model for e-commerce customer satisfaction has been illustrated. A case study has been done, as validation of presented method; finally, conclusion has been presented.

\section{Fuzzy Set Theory}

Fuzzy set theory provides a framework for handling the uncertainties. Zadeh initiated the fuzzy set theory (Zadeh L. A., 1965). Bellman presented some applications of fuzzy theories to the various decision-making processes in a fuzzy environment (Bellman R. E. \& Zadeh L. A., 1970). In non-fuzzy set every object is either a member of the set or it is not a member of the set but in fuzzy sets every object is to some extent member of a set and to some extent it is member of another set. Thus, unlike the crisp sets membership is a continuous concept in fuzzy sets. Fuzzy is used in support of linguistic variables and there is uncertainness in the problem. Fuzzy theory is widely applicable in information gathering, modeling, analysis, optimization, control, decision making, and supervision.

Special cases of fuzzy numbers include crisp real number and intervals of real numbers. Although there are many shapes of fuzzy numbers, the triangular and trapezoidal shapes are used most often for representing fuzzy numbers. The following describes and definitions show that membership function of triangular fuzzy number, trapezoidal fuzzy number, and its operations.

A fuzzy number $\tilde{A}$ is convex, if

$$
\mu_{\tilde{A}}\left[\lambda x_{1}+(1-\lambda) x_{2}\right] \geq \min \left[\mu_{\tilde{A}}\left(x_{1}\right), \mu_{\tilde{A}}\left(x_{2}\right)\right] . \quad x_{1}, x_{2} \in X, \lambda \in[0,1]
$$

Alternatively, a fuzzy set is convex if all a-level sets are convex. 
A fuzzy set $\tilde{A}$ in the universe of discourse X is normal if (A. Kaufmann \& M.M. Gupta, 1988, S. Mabuchi, 1988)

$$
\sup _{x} \mu_{\tilde{A}}(x)=1
$$

A nonempty fuzzy set $\tilde{A}$ can always be normalized by $\mu_{\tilde{A}}(x) / \sup _{x} \mu_{\tilde{A}}(x)$.

A triangular fuzzy number can be defined by $\tilde{A}=\left(a_{1}, a_{2}, a_{3}\right)$, where $a_{1} \leq a_{2} \leq a_{3}$, its member function represented as follows.

$$
\mu_{\tilde{A}}= \begin{cases}0 & x<a_{1} \\ \left(x-a_{1}\right) /\left(a_{2}-a_{1}\right) & a_{1} \leq x \leq a_{2} \\ \left(x-a_{3}\right) /\left(a_{3}-a_{2}\right) & a_{2} \leq x \leq a_{3} \\ 0 & x>a_{3}\end{cases}
$$

Let $\tilde{A}$ and $\tilde{B}$ be two fuzzy numbers parameterized by the $\left(a_{1}, a_{2}, a_{3}\right)$ and $\left(b_{1}, b_{2}, b_{3}\right)$, respectively. Then the operations of triangular fuzzy numbers are expressed as (S.J. Chen \& C.L. Hwang, 1992a):

$$
\begin{aligned}
& \tilde{A}(+) \tilde{B}=\left(a_{1}, a_{2}, a_{3}\right)+\left(b_{1}, b_{2}, b_{3}\right)=\left(a_{1}+b_{1}, a_{2}+b_{2}, a_{3}+b_{3}\right) \\
& \tilde{A}(-) \tilde{B}=\left(a_{1}, a_{2}, a_{3}\right)-\left(b_{1}, b_{2}, b_{3}\right)=\left(a_{1}-b_{1}, a_{2}-b_{2}, a_{3}-b_{3}\right) \\
& \tilde{A}(\times) \tilde{B}=\left(a_{1}, a_{2}, a_{3}\right) \times\left(b_{1}, b_{2}, b_{3}\right)=\left(a_{1} \times b_{1}, a_{2} \times b_{2}, a_{3} \times b_{3}\right) \\
& \tilde{A}(\div) \tilde{B}=\left(a_{1}, a_{2}, a_{3}\right) \div\left(b_{1}, b_{2}, b_{3}\right)=\left(a_{1} \div b_{3}, a_{2} \div b_{2}, a_{3} \div b_{1}\right)
\end{aligned}
$$

Triangular fuzzy numbers are appropriate for quantifying the vague information about most decision problems (C.H. Cheng \& Y. Lin, 2002), and the primary reason for using triangular fuzzy numbers can be stated as their intuitive and computational-efficient representation.

In this paper, the triangular fuzzy number is used for measuring customer satisfaction. More details about arithmetic operations laws of trapezoidal fuzzy number can be seen in (Lee et al., 2004).

Considering experts $E_{i}$ provide the satisfaction degree with $\tilde{A}^{(i)}$. The evaluation values given by each expert $\left(E_{i}\right)$ are presented in the form of a triangular fuzzy number:

$$
\tilde{A}^{(i)}=\left(a_{1}^{(i)}, a_{2}^{(i)}, a_{3}^{(i)}\right), \text { where } i=1,2, \ldots, n
$$

The average $\tilde{A}_{m}$ of all $\tilde{A}^{(i)}$ is computed using average means

$$
\tilde{A}_{m}=\left(a_{m 1}, a_{m 2}, a_{m 3}\right)=\left(\frac{1}{n} \sum_{i=1}^{n} a_{1}^{(i)}, \frac{1}{n} \sum_{i=1}^{n} a_{2}^{(i)}, \frac{1}{n} \sum_{i=1}^{n} a_{3}^{(i)}\right)
$$

For defuzzification of $\tilde{A}_{m}$, the following formula can be used: 


$$
A_{m}=\frac{a_{m 1}+2 a_{m 2}+a_{m 3}}{4}
$$

\section{The Model for E-Commerce Customer Satisfaction Evaluation}

\subsection{Determination of Indexes}

Some of the researches constructed evaluation index from commercial content, customer's concern, effective navigation, website design, safety, convenience, merchandise planning, contact convenience, customer service information, convenience of getting product information, accuracy, content relatedness, integrity, variety in displaying, information timely updating, easy application, system rapidity, service response in time, and guaranteed service (Duo Qi, 2003, Liu Peide, 2007, Yu Hongyan, 2006, Gao Dan, 2004, Gan Yong, 2006). Based on literature, this paper constructs customer satisfaction index of BtoC e-commerce enterprise, and evaluates customer satisfaction of BtoC e-commerce enterprise by adopting Fuzzy Triangular Numbers for Linguistic Variables and using fuzzy TOPSIS method Table1.

\begin{tabular}{|c|c|c|}
\hline Object & Indicator & Description \\
\hline \multirow{4}{*}{ Product } & Customization (Pr1) & The degree of customer needs satisfying \\
\cline { 2 - 3 } & Value (Pr 2) & The unique product characteristics \\
\cline { 2 - 3 } & Information (P r3) & Accessibility to the information of the products \\
\cline { 2 - 3 } & Scope (Pr 4) & The dimensions which the product satisfy them \\
\cline { 2 - 3 } & Accuracy of quality (Pr 5) & The quality parameters satisfaction \\
\hline \multirow{4}{*}{ Service } & Guaranty (Pr 6) & The confidence of the product quality \\
\cline { 2 - 3 } & Attitude (S1) & How services are received \\
\cline { 2 - 3 } & Information (S2) & Accessibility to the information of the services \\
\cline { 2 - 3 } & Distribution (S3) & The method and tools of service delivery \\
\cline { 2 - 3 } & Response and feedback (S4) & The quality of feedback of services \\
\cline { 2 - 3 } & Call center (S5) & Availability of a call center for customer care \\
\hline \multirow{4}{*}{ system } & Quality (S6) & The quality parameters satisfaction \\
\cline { 2 - 3 } & Management (S7) & Determination of service process and control indexes \\
\cline { 2 - 3 } & Safety (N1) & Security degree of networks \\
\cline { 2 - 3 } & Reliability (N2) & The amounts of risk \\
\cline { 2 - 3 } & Operability (N3) & Thetwork support of the customer needs \\
\cline { 2 - 3 } & Accessibility (N4) & The availability of network in 24*7 \\
\hline \multirow{4}{*}{ payment } & Humanization (N5) & Consideration of human computer interaction \\
\cline { 2 - 3 } & Accuracy of fee calculation (Pa1) & The trust in financial computation \\
\cline { 2 - 3 } & Accuracy of fee collection (Pa2) & The trust to the system of fee collection \\
\cline { 2 - 3 } & Method (Pa3) & The technical methods relating to the payment \\
\cline { 2 - 3 } & Facilities (Pa4) & The quality and suitability of facilities used for payment \\
\hline
\end{tabular}

Table 1. Indexes of e-commerce customer satisfaction evaluation

\subsection{Determination the Weight of Indexes}

TOPSIS (Technique for Order Preference by Similarity to an Ideal Solution) method is presented in Chen and Hwang (S.J. Chen \& C.L. Hwang, 1992b), with reference to Hwang and Yoon (C.L. Hwang \& K. Yoon, 1981). TOPSIS is a multiple criteria method to identify solutions from a finite set of alternatives. The basic principle is that the chosen alternative should have the shortest distance from the positive ideal solution and the farthest distance 
from the negative ideal solution. The procedure of fuzzy TOPSIS can be expressed in a series of steps:

E-commerce customer satisfaction is a typical Multi Criteria Decision Making (MCDM) problem. An MCDM problem can be formulated as follows:

$$
\begin{array}{r|ccccc}
X_{k}= & C_{1} & \ldots & C_{j} & \ldots & C_{n} \\
A_{1} & x_{11 k} & & x_{1, k} & & x_{1 n k} \\
\vdots & \vdots & & \vdots & & \vdots \\
A_{i} & x_{i 1 k} & \ldots & x_{i j k} & \ldots & x_{i n k} \\
\vdots & \vdots & & \vdots & & \vdots \\
A_{m} & x_{m 1 k} & \ldots & x_{m j k} & \ldots & x_{m n k} \\
W_{k} & =\left[\begin{array}{c}
w_{1 k} \\
\vdots \\
w_{j k} \\
\vdots \\
w_{n k}
\end{array}\right]
\end{array}
$$

where $K=1, \ldots, p$ decision makers select an alternative out of $i=1, \ldots, m$ alternatives $\left(A_{i}\right)$ according to $j=1, \ldots, n$ criteria $\left(C_{j}\right)$.

$x_{i j k}$ is the performance of alternative $A_{i}$ with respect to criterion $C_{j}$ estimated by decision maker $k$, while $W_{j k}$ is the weight of criterion $C_{j}$ given by the decision maker $k . X_{k}$ and $W_{k}$ are respectively the decision matrix and the weight vector for the decision maker $k$.

In the fuzzy TOPSIS procedure, the criteria weights $\left(\tilde{w}_{j}, j=1,2, \ldots\right.$ triangular fuzzy number of criteria) and characteristic values of alternatives at criteria $\left(\tilde{x}_{i j}, i=1,2, \ldots\right.$ number of alternatives, $j=1,2, \ldots$ number of criteria) are inputs and placed in matrix form (P. Sen \& J-B. Yang, 1998, C.-T. Chen, 2000, Fasanghari et al., 2008) as shown in step 1.

Step 1: Inputs are expressed in matrix format as;

$$
\left.\begin{array}{c}
{\left[\begin{array}{cccc}
\tilde{x}_{11} & \tilde{x}_{12} & \ldots & \tilde{x}_{1 n} \\
\tilde{x}_{21} & \tilde{x}_{22} & \ldots & \tilde{x}_{2 n} \\
\vdots & \vdots & \vdots & \vdots \\
\tilde{x}_{m 1} & \tilde{x}_{m 2} & \ldots & \tilde{x}_{m n}
\end{array}\right]} \\
\tilde{W}=\left[\tilde{w}_{1}, \tilde{w}_{2}, \ldots, \tilde{w}_{n}\right.
\end{array}\right]
$$

$\tilde{w}_{j}$ are triangular fuzzy numbers as $\tilde{w}_{j}=\left(w_{j 1}, w_{j 2}, w_{j 3}\right)$.

Step 2: the normalized decision matrix is constructed using equation (12) (H.S. Byun \& K.H. Lee, 2004, P. Sen \& J-B. Yang, 1998).

$$
\tilde{n}_{i j}=\frac{\tilde{x}_{i j}}{\sqrt{\sum_{i=1}^{n} \tilde{x}_{i j}^{2}}}
$$

Step 3: The weighted normalized decision matrix is, 


$$
\tilde{V}=\left[\tilde{v}_{i j}\right]_{m \times n}, i=1,2, \ldots, m, j=1,2, \ldots, n
$$

where,

$$
\tilde{v}_{i j}=\tilde{n}_{i j} \otimes \tilde{w}_{j}
$$

Set 4: each fuzzy number is defuzzified using equation(15). For triangular fuzzy number $\tilde{v}_{i j}=\left(a_{i j}, b_{i j}, c_{i j}\right)$ its defuzzification value is defined to be

$$
v_{i j}=\frac{a_{i j}+2 b_{i j}+c_{i j}}{4}
$$

And defuzzified weighted normalized matrix determined as $V=\left[v_{i j}\right]_{m \times n}, \quad i=1,2, \ldots, m$, $j=1,2, \ldots, n$.

Step 5: The ideal solution, $A^{+}\left(A_{i}^{+} ; i=1,2, \ldots, N\right)$, is made of all the best performance scores and the negative-ideal solution, $A^{-}\left(A_{i}^{-} ; i=1,2, \ldots, N\right)$, is made of all the worst performance scores at the measures in the defuzzified weighted normalized decision matrix. They ate calculated using equations (16) and (17). In these equations, the measures can be divided into two classes: the first is of an input or cost nature, so that smaller performance scores at these measure are preferred; the second is of an output or benefit nature and larger performance scores at these measures are preferred (H.S. Byun \& K.H. Lee, 2004, P. Sen \& JB. Yang, 1998).

$$
\begin{aligned}
& A^{+}=\left\{v_{1}^{+}, v_{2}^{+}, \ldots, v_{n}^{+}\right\}=\left\{\left(\max _{j} v_{i j} \mid j \in I\right),\left(\min _{j} v_{i j} \mid j \in J\right)\right\}, \\
& A^{-}=\left\{v_{1}^{-}, v_{2}^{-}, \ldots, v_{n}^{-}\right\}=\left\{\left(\min _{j} v_{i j} \mid j \in J\right),\left(\max _{j} v_{i j} \mid j \in I\right)\right\} .
\end{aligned}
$$

Step 6: The distance of an alternative $j$ to the ideal solution $\left(d_{i}^{+}\right)$, and from the negative ideal solution $\left(d_{i}^{-}\right)$are calculated using equation (18) and (19) (H.S. Byun \& K.H. Lee, 2004, P. Sen \& J-B. Yang, 1998).

$$
\begin{aligned}
& d_{i}^{+}=\sqrt{\sum_{j=1}^{m}\left(v_{i j}-v_{j}^{+}\right)^{2}} i=1,2, \ldots, n ; j=1,2, \ldots, m, \\
& d_{i}^{-}=\sqrt{\sum_{j=1}^{m}\left(v_{i j}-v_{j}^{-}\right)^{2}} i=1,2, \ldots, n ; j=1,2, \ldots, m
\end{aligned}
$$

Step 7: The ranking score $\left(R_{i}\right)$ is calculated using equation (20) (H.S. Byun \& K.H. Lee, 2004, P. Sen \& J-B. Yang, 1998).

$$
R_{i}=\frac{d_{i}^{-}}{d_{i}^{-}+d_{i}^{+}}, \quad i=1,2, . ., m
$$


The object of fuzzy TOPSIS method is to choose the alternatives that have the shortest distance from the positive ideal solution and the farthest distance from the negative ideal solution. Even though TOPSIS introduce two reference point, it does not consider the relative importance of the distance from the points (G.R. Jahanshahloo et al., 2006).

\section{Case study}

In order to assess the proposed methodology, we select 5 e-commerce websites as our alternatives and 10 customers which procure their needful. Experts fill in the questionnaire with fuzzy triangular numbers. Table 1 presents the index of the e-commerce assessment; we use these indexes for the selected websites assessment. As the first step, equation (10) is formed as Table 2. The weights of the indexes are equal in view point of the experts. Steps 2 , 3,4 and 5 are done and the defuzzified weighted normalized decision matrix, $A^{+}$, and $A^{-}$ is computed. In step 6 , the $d_{1}^{+}, d_{2}^{+}, d_{3}^{+}, d_{4}^{+}, d_{5}^{+}, d_{1}^{-}, d_{2}^{-}, d_{3}^{-}, d_{4}^{-}$, and $d_{5}^{-}$are calculated respectively: $3.6675,3.8247,2.9372,4.9262,5.3357,6.3497,7.4314,6.7605,5.3349$, and 4.2002. The final results of fuzzy TOPSIS method is obtained as $\mathrm{R}_{1}=0.6339, \mathrm{R}_{2}=0.6602, R_{3}=0.6971$, $R_{4}=0.5199$, and $R_{5}=0.4405$. Obviously, the third website (alternative number 3 ) is in first row of the website ranking and has the highest score in ranking. Unlike, the fifth website (alternative number 5) has the lowest score in ranking method of fuzzy TOPSIS.

\section{Conclusions}

The main contribution of this paper is proposing a ranking method for assessing the ecommerce under uncertain situations. In fact, combination of fuzzy triangular rubbers, TOPSIS method, and e-commerce indexes is proposed in this paper. Hence we can assess the customer satisfaction of e-commerce, and we run a case study in which the 5 ecommerce websites are assessed with 10 experts of e-commerce who are familiar with the selected websites. Fortunately, all of the experts are pleased of the obtained results. 


\begin{tabular}{|c|c|c|c|c|c|c|c|c|c|c|c|c|c|c|c|c|c|c|c|c|}
\hline \multirow[t]{2}{*}{ 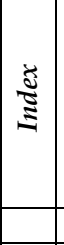 } & \multirow{2}{*}{ 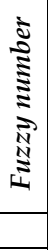 } & \multicolumn{5}{|c|}{ Alternatives } & \multirow[t]{2}{*}{ 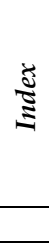 } & \multirow{2}{*}{ 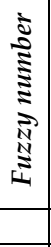 } & \multicolumn{5}{|c|}{ Alternatives } & \multirow[t]{2}{*}{$\stackrel{\Xi}{\Xi}$} & \multirow{2}{*}{ 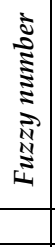 } & \multicolumn{5}{|c|}{ Alternatives } \\
\hline & & $A 1$ & $A 2$ & $A 3$ & \begin{tabular}{|l|}
$A 4$ \\
\end{tabular} & A5 & & & A1 & $A 2$ & $A 3$ & $A 4$ & A5 & & & A1 & A2 & $A 3$ & $A 4$ & $A 5$ \\
\hline \multirow{3}{*}{ Pr1 } & a1 & 8.06 & 0.98 & 6.13 & 3.72 & 5.55 & \multirow{3}{*}{ S3 } & a1 & 5.12 & 2.40 & 0.73 & 3.03 & 0.29 & \multirow{3}{*}{ N4 } & a1 & 6.82 & 7.52 & 2.64 & 4.67 & 2.41 \\
\hline & a2 & 9.54 & 7.95 & 8.67 & 4.70 & 9.27 & & a2 & 8.44 & 8.23 & 6.27 & 8.12 & 0.68 & & a2 & 9.50 & 8.15 & 9.32 & 7.89 & 3.71 \\
\hline & a3 & 9.87 & 9.29 & 8.92 & 7.51 & 9.67 & & a3 & 9.26 & 9.31 & 8.61 & 8.72 & 6.04 & & a3 & 9.90 & 9.19 & 9.64 & 9.44 & 5.51 \\
\hline \multirow{3}{*}{ Pr2 } & a1 & 1.45 & 1.98 & 9.62 & 0.69 & 7.20 & \multirow{3}{*}{ S4 } & a1 & 0.69 & 0.98 & 1.44 & 5.17 & 5.19 & \multirow{3}{*}{ N5 } & a1 & 1.80 & 4.53 & 5.77 & 3.42 & 7.64 \\
\hline & $\mathrm{a} 2$ & 4.39 & 6.06 & 9.65 & 8.26 & 8.18 & & a2 & 1.68 & 9.97 & 4.21 & 9.95 & 7.19 & & $\mathrm{a} 2$ & 3.99 & 5.56 & 7.98 & 5.41 & 8.82 \\
\hline & a3 & 8.11 & 9.99 & 9.84 & 8.77 & 9.67 & & a3 & 4.09 & 9.97 & 4.69 & 9.98 & 7.84 & & a3 & 6.14 & 5.66 & 8.85 & 7.45 & 9.47 \\
\hline \multirow{3}{*}{$\operatorname{Pr} 3$} & a1 & 7.52 & 6.49 & 1.62 & 4.89 & 1.68 & \multirow{3}{*}{ S5 } & a1 & 6.51 & 3.16 & 4.08 & 9.59 & 9.57 & \multirow{3}{*}{ Pa1 } & a1 & 0.78 & 5.83 & 3.34 & 4.50 & 4.42 \\
\hline & a2 & 9.18 & 9.45 & 9.44 & 8.36 & 2.38 & & a2 & 9.16 & 5.15 & 5.09 & 9.70 & 9.98 & & a2 & 1.97 & 9.10 & 7.54 & 9.74 & 5.44 \\
\hline & a3 & 9.78 & 9.79 & 9.57 & 8.80 & 7.35 & & a3 & 9.66 & 6.37 & 7.01 & 9.84 & 9.98 & & a3 & \begin{tabular}{|l|}
8.39 \\
\end{tabular} & 9.97 & 8.25 & 9.82 & 7.41 \\
\hline \multirow{3}{*}{ Pr4 } & a1 & 1.37 & 1.00 & 8.52 & 4.97 & 3.41 & \multirow{3}{*}{ S6 } & a1 & 5.96 & 1.92 & 2.27 & 9.30 & 2.66 & \multirow{3}{*}{$\mathrm{Pa} 2$} & a1 & \begin{tabular}{|l|}
6.32 \\
\end{tabular} & 7.56 & 3.40 & 1.85 & 1.73 \\
\hline & a2 & 5.92 & 4.30 & 9.08 & \begin{tabular}{|l|}
9.73 \\
\end{tabular} & 6.58 & & a2 & 6.43 & 9.50 & 9.45 & 9.56 & 7.81 & & $\mathrm{a} 2$ & \begin{tabular}{|l|}
7.06 \\
\end{tabular} & 9.29 & 8.57 & 6.90 & 1.81 \\
\hline & a3 & 8.89 & 8.67 & 9.59 & \begin{tabular}{|l|}
9.98 \\
\end{tabular} & 8.60 & & a3 & 8.67 & 9.72 & 9.51 & 9.63 & 9.94 & & a3 & \begin{tabular}{|l|}
7.72 \\
\end{tabular} & 9.97 & 9.76 & 8.51 & 7.14 \\
\hline \multirow{3}{*}{$\operatorname{Pr} 5$} & a1 & 5.70 & 3.65 & 8.27 & \begin{tabular}{|l|}
8.78 \\
\end{tabular} & 6.27 & \multirow{3}{*}{ S7 } & a1 & 8.96 & 9.35 & 6.78 & 1.12 & 2.40 & \multirow{3}{*}{$\mathrm{Pa} 3$} & a1 & \begin{tabular}{|l|}
9.47 \\
\end{tabular} & 9.04 & 5.06 & 8.04 & 6.39 \\
\hline & a2 & 6.95 & 4.92 & 9.05 & 9.42 & 9.47 & & a2 & 9.79 & 9.75 & 7.24 & 3.49 & 7.54 & & $\mathrm{a} 2$ & 9.70 & 9.10 & 8.36 & 9.39 & 7.73 \\
\hline & a3 & 7.10 & 9.95 & 9.75 & \begin{tabular}{|l|}
9.48 \\
\end{tabular} & 9.74 & & a3 & 9.87 & 9.99 & 9.37 & 5.09 & 8.17 & & a3 & \begin{tabular}{|l|}
9.94 \\
\end{tabular} & 9.25 & 8.75 & 9.67 & 8.76 \\
\hline \multirow{3}{*}{ Pr6 } & a1 & 5.29 & 8.33 & 9.67 & 1.23 & 5.28 & \multirow{3}{*}{$\mathrm{N} 1$} & a1 & 7.22 & 9.96 & 0.89 & 4.85 & 0.36 & & a1 & \begin{tabular}{|l|}
7.48 \\
\end{tabular} & \begin{tabular}{|l|}
8.38 \\
\end{tabular} & 7.18 & 0.72 & 4.36 \\
\hline & a2 & 7.95 & 9.72 & 9.80 & 3.95 & 6.60 & & a2 & 9.80 & 10.00 & 8.21 & 5.92 & 2.19 & $\mathrm{~Pa} 4$ & a2 & \begin{tabular}{|l|l|}
7.80 \\
\end{tabular} & 9.97 & 8.74 & 4.58 & 8.74 \\
\hline & a3 & 9.87 & 9.77 & 9.95 & \begin{tabular}{|l|l|} 
\\
\end{tabular} & 9.25 & & a3 & 9.85 & 10.00 & 9.62 & 6.57 & 6.68 & & a3 & 8.39 & \begin{tabular}{|c|}
9.97 \\
\end{tabular} & 9.77 & 4.90 & 9.14 \\
\hline & a1 & 7.99 & 6.15 & 6.14 & 5.82 & 4.61 & & a1 & 7.04 & 7.43 & 7.64 & 2.24 & 8.18 & & & & & & & \\
\hline S1 & $\mathrm{a} 2$ & 8.51 & 6.28 & 7.95 & 6.68 & 9.06 & N2 & a2 & 9.78 & 9.47 & 8.35 & 6.88 & 9.01 & & & & & & & \\
\hline & a3 & 9.66 & 7.32 & 9.47 & 6.88 & 9.29 & & a3 & 9.87 & 9.51 & 9.26 & 8.36 & 9.73 & & & & & & & \\
\hline & a1 & 5.01 & 0.80 & 6.35 & 1.58 & 0.33 & & a1 & 5.82 & 4.63 & 5.96 & 9.24 & 9.42 & & & & & & & \\
\hline S2 & a2 & 8.75 & 2.14 & 7.78 & \begin{tabular}{|l|}
7.92 \\
\end{tabular} & 4.56 & N3 & a2 & 9.44 & 6.75 & 7.54 & 9.36 & 9.72 & & & & & & & \\
\hline & a3 & 8.98 & 3.69 & 8.50 & \begin{tabular}{|l|}
9.48 \\
\end{tabular} & 9.21 & & a3 & 9.50 & 6.87 & 8.14 & 9.94 & 9.75 & & & & & & & \\
\hline
\end{tabular}

Table 2. E-commerce customer satisfaction value for the 5 selected e-commerce website

\section{References}

A. Kaufmann \& M.M. Gupta (1988). Fuzzy Mathematical Models in Engineering and Management Science, North-Holland, Amsterdam

Bellman R. E. \& Zadeh L. A. (1970). Decision making in a fuzzy environment. Management Sciences, Vol. 17, 141-164

C.-T. Chen (2000). Extensions of the Topsis for group decision-making under fuzzy environment. Fuzzy Sets and Slstems, Vol. 114, 1-9

C. Albert (2002). Service Loyalty: the effects of service quality and the mediating role of customer satisfaction. Eur. J. Market. , Vol. 36, 810-823

C. Fornell (1992). A national customer satisfaction barometer: the swedish experience. J. Market., Vol. 56, 6-21

C.H. Cheng \& Y. Lin (2002). Evaluating the best main battle tank using fuzzy decision theory with linguistic criteria evaluation. European journal of operation research, Vol. 142, No. 2, 174-176 
C.L. Hwang \& K. Yoon (1981) Multiple Attribute Decision Making Methods and Applications. Berlin Heidelberg, Springer.

D.J. Michael (2004). Determining attribute importance in a service satisfaction model. J. Serv. Res., Vol. 7, 124-141

Duo Qi (2003). Analyse and design on customer satisfactory system under E-commerce. SciTechnology and Management, Vol. 1

E.W. Anderson \& C. Fornell (2000). Foundations of the American Customer Satisfaction Index. Total Qual. Manag, Vol. 11 869-882

Fasanghari, M.; Gholamy, N.; Chaharsooghi, S. K.; Qadami, S. \& Delgosha, M. S. (2008). The Fuzzy Evaluation of E-Commerce Customer Satisfaction Utilizing Fuzzy TOPSIS, Proceeding of International Symposium on Electronic Commerce and Security (ISECS 2008), pp. 870-874, China, IEEE Computer Society, China

Fasanghari, M. \& Roudsari, F. H. (2008). The Fuzzy Evaluation of E-Commerce Customer Satisfaction. World Applied Sciences Journal, Vol. 4, No. 2, 164-168

G.R. Jahanshahloo; F. Hossenzadeh Lotfi \& M. Izadikhah (2006). An algorithm method to extend TOPSIS for decision-making problems with interval data. Applied Mathematics And Computation, Vol. 175, 1375-1384

Gan Yong (2006) Research on the Fuzzy Comprehensive Evaluation of Customer Satisfaction in B2C Electronic Business Enterprise. Maseter dissertation of Jilin Unversity.

Gao Dan (2004) Simple analyse on evaluation indicator system of Custom Satisfaction in Ecommerce. China ECommerce.

H.S. Byun \& K.H. Lee (2004). A decision support system for the selection of a rapid prototyping process using the modified TOPSIS method. International Journal of Advanced Manufacturing Technology, 1-10

Lee, J. W.; Hong, E. \& Park, J. (2004). A Q-learning based approach to design of intelligent stock trading agents. Engineering Management Conference, Proceedings. IEEE International, Vol. 3, 1289-1292

Liu, P. (2007). Evaluation Model of customer Satisfaction B2C E-Commercebased on Combination of Linguistic Variables And Fuzzy Triangular Numbers, Proceeding of eight ACIS international conference on software engineering, artificial intelligence, networking, and parallel/ distributed computing, pp. 450-454

Liu Peide (2007). Evaluation Model of Customer Satisfaction of B2C E_Commerce Based on Combination of Linguistic Variables and Fuzzy Triangular Numbers, Proceeding of Eighth ACIS International Conference, pp. 450-454, Qingdao, China, Qingdao, China

M. Wang (2003). Assessment of e-service quality via e-satisfaction in e-commerce globalization. The Electr. J. Inform. Syst. Develop. Countries Vol. 11, No. 10, 1-4

Mihelis, G.; Grigoroudis, E. \& Siskos, Y. (2001). Customer satisfaction measurement in the private bank section. European Journal of Operation Research, Vol. 130, 347-360

P. Hackl; K. Kristensen \& A.H. Westlund (Eds.) (2000). Customer Satisfaction: Theory and Measurement. JSpecial Issue of ournal of Total Quality Management

P. Sen \& J-B. Yang (1998). Multiple Criteria Decision Support in Engineering Design, Springer Verlag London Limited, London, Great Britain

S.-H. Hsu (2008). Developing an index for online customer satisfaction: Adaptation of American Customer Satisfaction Index. Expert Systems with Applications, Vol. 34, 3033-3042 
S. Mabuchi (1988). An approach to the comparison of fuzzy subsets with an a-cut dependent index. IEEE Transactions on Systems, Man, and Cybernetics SMC, Vol. 18, No. 2, 264272

S.J. Chen \& C.L. Hwang (1992a). Fuzzy Multiple Attribute Decision Making: Methods and Application, Springer, New York

S.J. Chen \& C.L. Hwang (1992b) Fuzzy Multiple Attribute DecisionMaking:Methods and Applications. Berlin, Springer-Verlag.

Xiaohong Liu; Xianyi Zeng; Yang Xu \& Ludovic Koehl (2008). A fuzzy model of customer satisfaction index in e-commerce. Mathematics and Computers in Simulation, Vol. 77 512-521

Yan Xiao-Tian \& Wei Hong-Jun (2005). Construction and application of power customer satisfaction degree evaluation system. East China Electric Power, Vol. 33, No. 12, 5255

Yin Rongwu (2000). review of customer satisfactory Index in US. World Standardization $\mathcal{E}$ Quality Management, Vol. 1, No. 1, 7-10

Yu Hongyan (2006). Brief Analysis on Custom Satisfaction BtoC in E-commerce. Journal of Hunan University of Science and Engineering, Vol. 1

Zadeh L. A. (1965). Fuzzy sets. Information and Control, Vol. 8, 338-353

Zhao Pengxiang (2001). Research on Building and Performance of Customer Satisfaction Management System. World Standardization \& Quality Management, Vol. 6, No. 6, 10 13

Zheng Yue-Fang (2005). Customer satisfaction-the most important task of electricity service. China Quality, Vol. 3, No. 65-66 


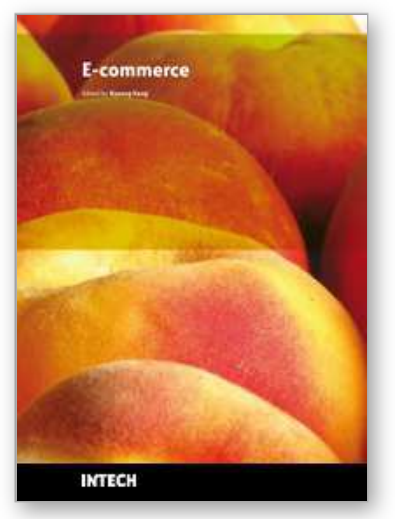

\author{
E-commerce \\ Edited by Kyeong Kang
}

ISBN 978-953-7619-98-5

Hard cover, 284 pages

Publisher InTech

Published online 01, February, 2010

Published in print edition February, 2010

E-commerce provides immense capability for connectivity through buying and selling activities all over the world. During the last two decades new concepts of business have evolved due to popularity of the Internet, providing new business opportunities for commercial organisations and they are being further influenced by user activities of newer applications of the Internet. Business transactions are made possible through a combination of secure data processing, networking technologies and interactivity functions. Business models are also subjected to continuous external forces of technological evolution, innovative solutions derived through competition, creation of legal boundaries through legislation and social change. The main purpose of this book is to provide the reader with a familiarity of the web based e-commerce environment and position them to deal confidently with a competitive global business environment. The book contains a numbers of case studies providing the reader with different perspectives in interface design, technology usage, quality measurement and performance aspects of developing web-based e-commerce.

\title{
How to reference
}

In order to correctly reference this scholarly work, feel free to copy and paste the following:

Mehdi Fasanghari (2010). E-Commerce Assessment in Fuzzy Situation, E-commerce, Kyeong Kang (Ed.), ISBN: 978-953-7619-98-5, InTech, Available from: http://www.intechopen.com/books/e-commerce/ecommerce-assessment-in-fuzzy-situation

\section{INTECH}

open science | open minds

\section{InTech Europe}

University Campus STeP Ri

Slavka Krautzeka 83/A

51000 Rijeka, Croatia

Phone: +385 (51) 770447

Fax: +385 (51) 686166

www.intechopen.com

\section{InTech China}

Unit 405, Office Block, Hotel Equatorial Shanghai

No.65, Yan An Road (West), Shanghai, 200040, China

中国上海市延安西路65号上海国际贵都大饭店办公楼 405 单元

Phone: +86-21-62489820

Fax: $+86-21-62489821$ 
(C) 2010 The Author(s). Licensee IntechOpen. This chapter is distributed under the terms of the Creative Commons Attribution-NonCommercialShareAlike-3.0 License, which permits use, distribution and reproduction for non-commercial purposes, provided the original is properly cited and derivative works building on this content are distributed under the same license. 